\title{
Construção de um aparato de baixo custo para medir ângulo de contato
}

\author{
Construction of a low cost apparatus to measure contact angle
}

\author{
Enoque de Sousa Barbosa ${ }^{1}$ \\ Valéria Castelo Branco de Sousa ${ }^{2}$ \\ Victor Montero Del Aguila ${ }^{3}$
}

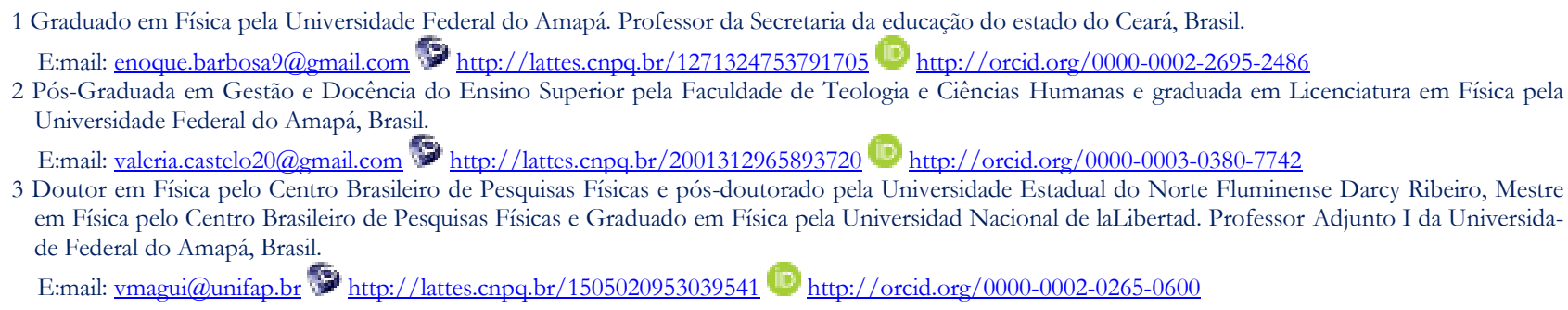

RESUMO: Este trabalho teve como objetivo a construção de um aparato de baixo custo capaz de medir ângulo de contato. Para a construção do mesmo utilizou-se material de "sucata", bem como alguns itens de armarinho e outras peças tais como tarraxa de violão. Após a construção foi realizada a coleta de dados e, quantitativamente, utilizando-se de métodos estatísticos, obtiveram-se os valores de ângulo de contato. Com isso, foi observado que o aparato mostrou-se capaz de realizar medidas satisfatórias de ângulos de contato em três superfícies, sendo que os valores obtidos neste trabalho foram de $45,3^{\circ} \pm 0,9^{\circ}$ e $45,2^{\circ} \pm 1,5^{\circ}$ entre água e o vidro, $158,5^{\circ} \pm 0,3^{\circ}$ e $157,6^{\circ} \pm 0,9^{\circ}$ entre a água e a superfície foliar da planta Thalia geniculata (Marantaceae), mostrando resultados coerentes com demais resultados obtidos a partir de equipamentos profissionais. Ao realizar um estudo sobre a planta Colocasia antiquorum schottpara (Tajá) obtiveram-se ângulos de contato de $167,8^{\circ} \pm 1,4^{\circ}$ e $160,4^{\circ} \pm 4^{\circ}$ entre a água e a superfície foliar da planta, sendo este o maior ângulo formado no contato da gota de água e uma superfície foliar reportado na literatura brasileira.

Palavras Chave: Ângulo de contato. Superhidrofóbico. Aparato de baixo custo.

\begin{abstract}
This work aimed at the construction of a low cost apparatus capable of measuring contact angle. For its construction it was used "scrap material", as well as some haberdasher items and other parts like guitar tuning pegs. After the construction the data collection was performed and, quantitatively, using statistical methods, the values of the contact angles were found. Thus, it was observed that the apparatus showed to be able to perform satisfactory measurements of contact angles in three different surfaces, in which the values obtained in this work were $45.3^{\circ} \pm 0.9$ and $45.2^{\circ} \pm 1.5$ between water and glass, $158.5^{\circ} \pm 0.3$ and $157.6^{\circ} \pm 0.9$ between the water and the leaf surface of the Thalia geniculate (Marantaceae) plant, showing consistency with results obtained from professional equipments. Performing a study on the Colocasia antiquorum schottpara (Tajá) plant it were obtained contact angles of $167.8^{\circ} \pm 1.4$ and $160.4^{\circ} \pm 4$ between the water and the leaf surface of the plant, those being the largest angles formed in the contact of the drop of water and a foliar surface reported in Brazilian literature.
\end{abstract}

Keywords: Contact angle. Superhydrophobic. Low cost apparatus.

\section{INTRODUÇÃO}

Falando-se em superfícies e suas proprie- dades não se pode deixar de mencionar a sua molhabilidade (que está relacionada ao quanto um líquido pode espalhar-se sobre uma super- 
fície), e que os estudos relacionados à mesma podem englobar um conjunto de conceitos ligados a quase todos os ramos da Física. Essa molhabilidade é definida através de um ângulo $(\theta)$ conhecido como ângulo de contato, onde, dependendo do valor desse ângulo, a superfície pode ser caracterizada como liofóbica ou liofílica. Caso o líquido seja a água, é caracterizado como hidrofóbica ou hidrofílica (FERREIRA, 2003; DORING et al.,2013).

Os primeiros modelos utilizados para o estudo da superhidrofobicidade de superfícies surgiram na primeira metade do séc. XX a partir dos trabalhos de Wenzel, Cassie e Baxter. Contudo, foi graças a dois trabalhos importantíssimos que se alavancou o estudo pelas superfícies hidrofóbicas e hidrofílicas. Um de Onda et. al. publicado em 1996, onde este dizia que a superhidrofobicidade estava relacionada à existência de estruturas fractais e o outro de Barthlott e Neinhuis que descrevera a característica superhidrofóbica da flor de lótus. Chamando assim o interesse pelo assunto, principalmente, de grupos empresariais privados como Toyota, Nissan Motor CO LTDA, Toshiba KK, Sony Corporation, Fuji Film, entre outras, sendo que esses grupos são proprietários da maior parte de patentes referentes ao assunto (BURKARTER, 2010; FERREIRA, 2013).

Para encontrar o ângulo de contato é necessário um aparato para medi-lo, esse aparato é conhecido como goniômetro, contudo, o custo de um equipamento capaz de fazer essa medida gira em torno de $\mathrm{R} \$ 20.000,00$ (vinte mil reais). Deste modo, o objetivo deste trabalho é construir um aparato de baixo custo capaz de medir ângulo de contato, para então dizer se a superfície é hidrofóbica ou hidrofílica.

\section{FUNDAMENTO TEÓRICO}

Podemos definir a molhabilidade de uma superfície como uma medida do quanto o líquido pode espalhar-se sobre ela ou do quanto o líquido fica retido em uma superfície, pois, dependendo da estrutura da superfície a mesma não é molhável e sim apenas retém o líquido. Esse espalhamento é definido por um parâmetro chamado ângulo de contato $(\theta)$, que é medido entre a linha que tangência a gota nas imediações da superfície e a linha horizontal onde a superfícies se encontra, como mostra a Figura 1.1. No caso da água, classifica-se as superfícies como hidrofóbicas, quando o ângulo de contato é maior que 90 graus, e hidrofílicas, quando o ângulo de contato é menor que 90 graus. Há também casos extremos, mostrados na Figura 1.1, quando o ângulo de contato é superior a $150^{\circ}$ (cento e cinquenta graus) a superfície é chamada superhidrofóbica e quando este ângulo é menor que $10^{\circ}$ (dez graus) a superfície é chamada superhidrofílica. Outro parâmetro associado a caracterização da molhabilidade é a histerese de ângulo de contato, que está associada a facilidade ou dificuldade de uma gota deslizar (ou rolar) para fora de uma superfície. As superfícies superhidrofóbicas possuem baixa histerese de ângulo de contato, isso quer dizer que aágua desliza com maior facilidade sobre elas (BURKARTER, 2006; BURKARTER, 2010; FERREIRA, 2013).

Figura 1.1: Condições de molhabilidade de uma superfície: a) superfície superhidrofílica $\theta=0$ grau; b) superfície com molhabilidade parcial 150 graus $>\theta>10$ grause c) superfície superhidrofóbica $\theta=180$ graus.

Figure 1.1: Wett ability conditions of a surface: a) superhydrophilic surface $\theta=0$ degree; b) surface with partial wett ability 150 degrees $>\theta>10$ degrees and $\mathbf{c}$ ) superhydrophobic surface $\theta=180$ degrees

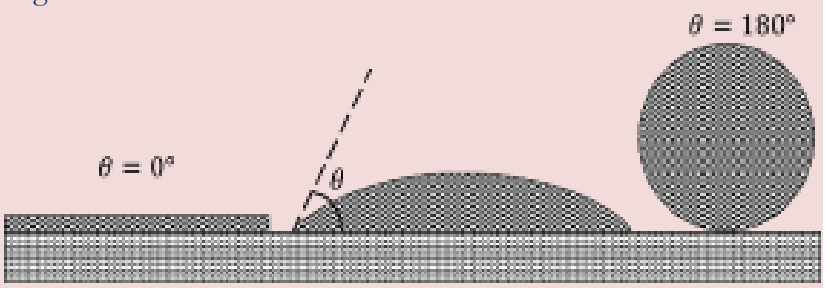

(a)

(b)

(c)

Fonte: Os autores adaptada de Burkarter.

Os estudos ligados à molhabilidade de su- 
perfícies iniciaram-se por volta do séc. XIX. Pois, em 1805, Thomas Young obteve uma equação que associa parâmetros no efeito de interação entre sólido e líquido em um estudo com base na ideia de equilíbrio de forças. Essa equação ficou conhecida como Equação de Young mostrada na expressão (1.1), relacionando o ângulo de contato $(\theta)$ entre um líquido e uma superfície sólida através das tensões interfaciais líquido-vapor $\left(\gamma_{L V}\right)$, sólido-vapor $\left(\gamma_{S V}\right)$ e sólido-líquido $\left(\gamma_{S L}\right)$. Mais tarde Gauss introduziu o conceito de balanço de energia de superfície aplicado ao fenômeno da capilaridade em 1830, mas foi em 1880 que a Equação de Young ganhou uma base matemática mais sólida graças aos trabalhos de Gibbs relacionados à termodinâmica (BURKARTER, 2010).

Figura 1.2: Definição do ângulo de contato e tensões superficiais presentes na equação de Young.

Figure 1.2: Definition of the contact angle and surface tensions present in Young's equation.

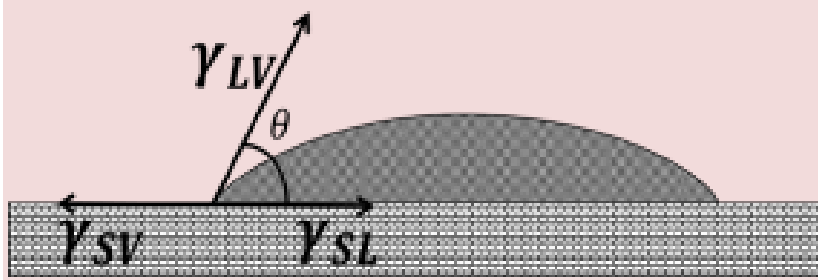

Fonte: Os autores adaptada de Burkarter.

$$
\gamma_{L V} \cos \theta=\gamma_{S V}-\gamma_{S}
$$

Desta forma os trabalhos de Willard Gibbs, em 1880, indicaram que a tensão superficial resulta de uma energia livre para realização de trabalho sobre as vizinhanças, que pode ser associada aos átomos da superfície. Assim para uma melhor compreensão dos fenômenos que estão ligados à molhabilidade, será apresentado na próxima seção a histerese de ângulo de contato.

\subsection{Histerese de Ângulo de Contato}

Um aspecto importante para avaliar a molhabilidade de uma determinada superfície é a

histerese do ângulo de contato. Esta é uma medida da aderência de uma gota à superfície que se obtém através da diferença entre o ângulo de contato de avanço e o de recuo, enquanto a gota se arranja à superfície, o ângulo de contato pode assumir um comportamento dinâmico, ou seja, quando o líquido é adicionado, o ângulo de contato pode aumentar, com isso, chama-se de ângulo de avanço $\left(\theta_{A}\right)$. No caso dele retrair-se quando uma porção do líquido é retirada chama-se de ângulo de recuo $\left(\theta_{R}\right)$. Ambos os casos estão ilustrados na Figura 1.3. Com base neste conceito ligado aos ângulos de avanço e de recuo, destaca-se uma das técnicas de caracterização em trabalhos na área da molhabilidade e é conhecido como o estudo da chamada histerese de ângulo de contato da superfície $(\delta \theta)$ (BURKARTER, 2010; FERREIRA, 2013).

Onde:

$$
\delta \theta=-\theta
$$

Há também um parâmetro de classificação da histerese de ângulo de contato conhecido como ângulo de deslizamento. A Figura 1.3 mostra a relação entre o ângulo de deslizamento com os ângulos de avanço e de recuo:

Figura 1.3: Definição dos ângulos utilizados na determinação da histerese de ângulo de contato: a) ângulo de avanço $\left(\theta_{A}\right)$; b) ângulo de recuo $\left(\theta_{R}\right)$.

Figure 1.3: Definition of the angles used in the determination of contact angle hysteresis: a) angle of advance

$\left.\left(\theta \_A\right) ; b\right)$ angle of recoil $\left(\theta \_R\right)$.

a)

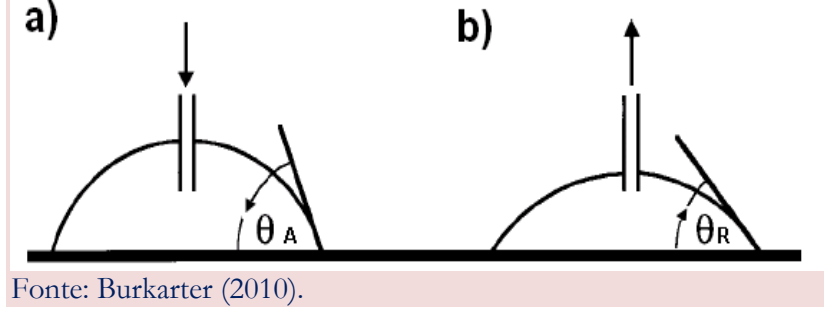

$$
\sin \alpha=C \gamma_{L V}\left(\cos \theta_{A}-\cos \theta_{R}\right)
$$

Sendo $\boldsymbol{C}=\boldsymbol{w} / \boldsymbol{m} \boldsymbol{g}$, onde $\boldsymbol{g}$ é a aceleração da gravidade, $\boldsymbol{m}$ a massa da gota e $\boldsymbol{w}$ é o diâ- 
metro da zona de molhamento. Porém, há dificuldade associada a esta relação, pois a determinação da constante $C$ é feita por métodos empíricos. Para superfícies superhidrofóbicas o valor de $\delta \theta$ é muito pequeno, podendo ser mais um parâmetro de caracterização deste tipo de superfície (BURKARTER, 2010; FERREIRA, 2013).

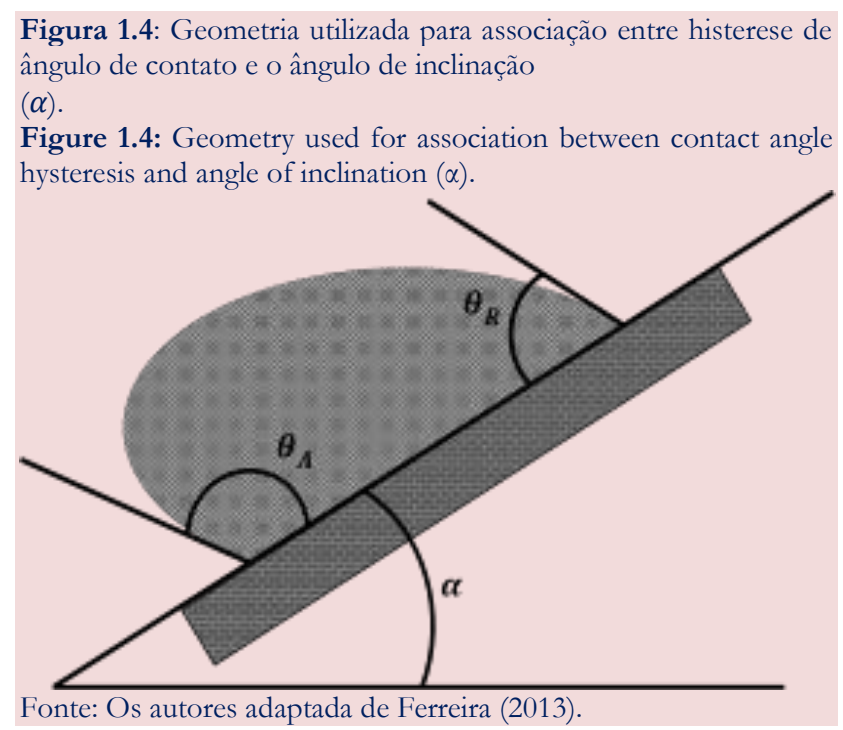

Muitos trabalhos relacionados ao desenvolvimento de superfícies superhidrofóbicas apresentam medidas do ângulo de deslizamento $(\alpha)$ como argumento para indicar o quão baixa é a histerese de ângulo de contato, pois há dificuldades de medida. Neste caso, considera-se que a histerese de ângulo de contato é baixa quando $\theta_{A} \approx \theta_{R}$, ou seja, a gota desliza ou rola sobre a superfície com mais facilidade. Portanto, quanto menor o ângulo de deslizamento $(\alpha)$, menor será a histerese de ângulo de contato (BURKARTER, 2010; FERREIRA, 2013).

\section{CONSTRUÇÃO DO APARATO}

Para a construção do aparato optou-se por usar um microscópio, pois o mesmo possui três graus de liberdade possibilitando assim um total controle sobre o foco da amostra e também suas lentes possuem um poder de aumento da imagem de 50 (cinquenta) até 1500 (mil e quinhentas) vezes.

A construção do aparato divide-se em três partes, aquisição do material, limpeza e então a montagem. A seguir detalhar-se-á a construção do aparato ressaltando os pontos mais importantes, desde a aquisição dos materiais até a montagem.

\subsection{Aquisição e Limpeza do Mate- rial}

Adquiriu-se o microscópio (que é o material com maior custo e, portanto, mais difícil de se encontrar/adquirir) no Almoxarifado da Universidade Federal do Amapá, onde haviam vários e os mesmos estavam prestes a serem jogados fora.

A escolha do microscópio utilizado pela presente pesquisa foi o modelo Microscópio Binocular Studar Profissional 220v (duzentos e vinte volts), pois, o mesmo se adequava as nossas necessidades, entre elas uma certa estabilidade, onde o mesmo ficaria deitado sobre a mesa e sua parte elétrica não interessaria aqui, porquê, a iluminação sobre a amostra vem de uma fonte externa.

Foi adquirido uma tarraxa de violão em uma loja de manutenção de violões. $\mathrm{O}$ intuito da tarraxa é pôr mais um grau de liberdade no instrumento, com isso é possível ter uma melhor visualização da imagem da gota sobre a superfície para a obtenção do ângulo de contato. A placa de alumínio e o vidro foram adquiridos em uma vidraçaria (loja de vidros e alumínios) sendo que os mesmos foram doados. $\mathrm{E}$ por fim adquiriu-se duas seringas, a seringa de insulina utilizada aqui foi comprada em uma farmácia onde custou menos de $\mathrm{R} \$$ 2,00 (dois reais) e a micro seringa foi comprada pela internet no valor de $\mathrm{R} \$ 190,00$ (cento e noventa reais).

Após a aquisição dos materiais foi feito a limpeza dos mesmos, onde, o microscópio foi limpo apenas com papel higiênico e água e as 
peças desgastadas pelo tempo foram trocadas por outras dos outros microscópios adquiridos no Almoxarifado. A partir daí seguiu- se com a construção/montagem do aparato.

\subsection{Montagem do Aparato} de:

Para a montagem do aparato precisou-se

- Supercola;

- Pistola e bastão de cola quente;

- Microscópio;

- Duas placas de alumínio A e B, onde o tamanho das placas são suficientes para alojar a tarraxa e as amostras respectivamente;

- Uma tarraxa de violão;

- Uma serra de ferro;

- Uma câmera fotográfica;

- Uma lanterna;

- Fita adesiva.

Com o auxílio de uma serra, foi feita uma abertura na tarraxa. Com a tarraxa é possível por mais um grau de liberdade no aparato para melhorar o manuseio do mesmo na hora de tomar-se as fotografias da gota. Em seguida, a placa de alumínio B foi presa com cola quente na abertura feita com a serra na tarraxa.

Figura 2.1: A placa de alumínio B foi presa com cola quente na abertura da tarraxa.

Figure 2.1: The aluminum plate $\mathrm{B}$ was secured with hot glue in the opening of the spindle.

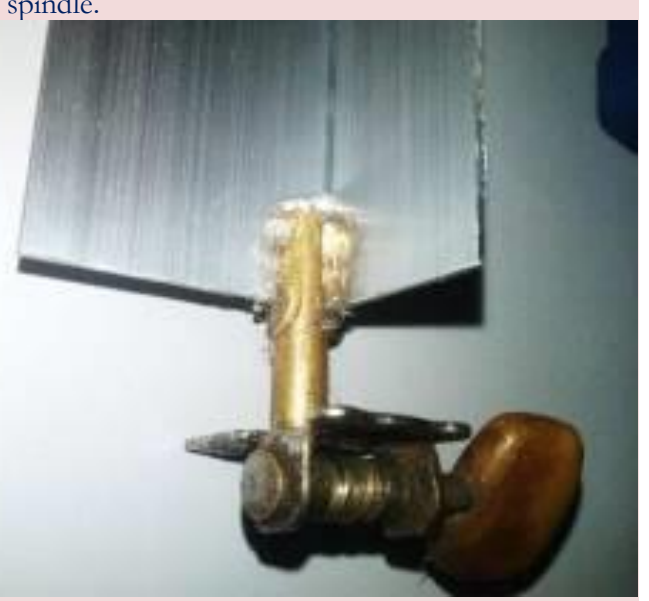

Fonte: Os autores.
Com supercola a placa de alumínio A foi acoplada ao microscópio, a intenção com esta placa de alumínio é criar uma base para então prender a tarraxa na mesma. Logo após, na placa de alumínio A prendeu-se a tarraxa com supercola, sendo que a mesma está presa à placa de alumínio B.

Figura 2.2: Placa de alumínio $B$ que está presa à uma tarraxa, sendo que esta, por sua vez está presa à placa de alumínio A.

Figure 2.2: Aluminum plate $B$ that is attached to a spindle, which in turn is attached to the aluminum plate $\mathrm{A}$.

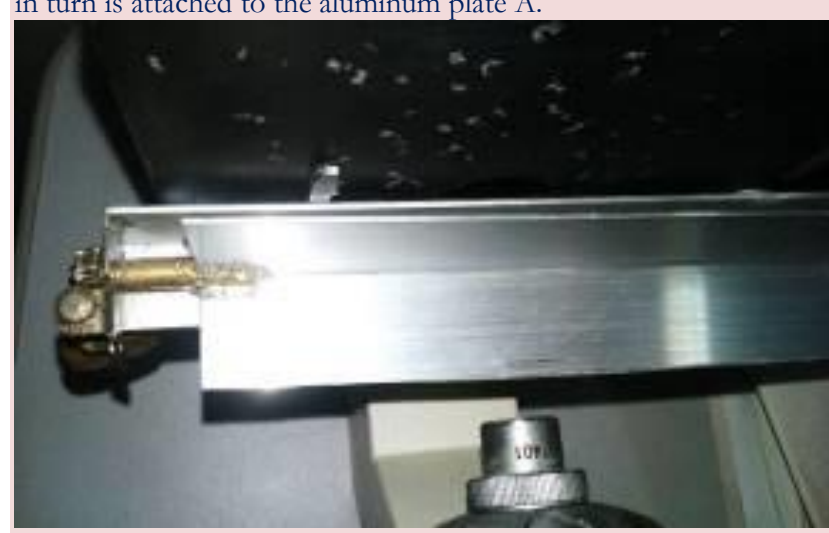

Fonte: Os autores.

Prendeu-se a lanterna com fita adesiva no microscópio, o intuito da lanterna é por uma iluminação externa que independe da parte elétrica do microscópio. Por fim, a amostra foi colocada sobre a placa de alumínio, neste caso a amostra é uma placa de vidro.

Figura 2.3: Amostra sobre a placa de alumínio.

Figure 2.3: Sample on aluminum plate.

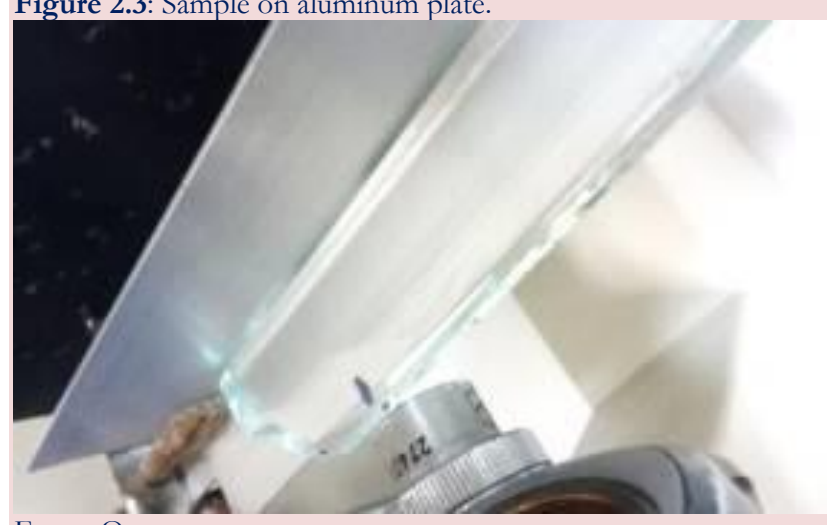

Fonte: Os autores.

Com isso o aparato está concluído e pronto para ser usado, a Figura 2.4 mostra ele finalizado. 
Figura 2.4: Construção do aparato finalizado. A figura (a) mostra o aparato de perfil e a figura (b) mostra o aparato de lado. Figure 2.4: Construction of finished equipment. Figure (a) shows the profile apparatus and figure (b) shows the apparatus on its side.

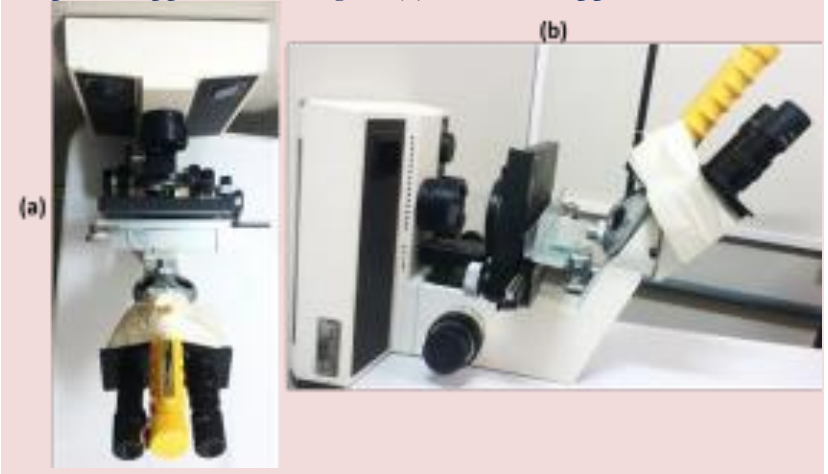

Fonte: Os autores.

\section{METOdOLOGIA E DISCUSSÃO}

As gotas foram depositadas sobre o vidro com dois tipos de seringas, uma de insulina, pois, a mesma tem o controle do volume mais preciso que as demais dispostas em farmácias e a outra uma micro seringa de $10 \mu \mathrm{l}$ (dez microlitros), sendo o controle do volume desta maior que o controle do volume da seringa de insulina.

Logo após ao depositar as gotas sobre o vidro, foram tiradas fotografias com a câmera da marca Sony onde a resolução era de no máximo $8 \mathrm{mpx}$ (oito megapixels), graças ao poder de aumento do microscópio, as imagens da gota foram ampliadas em 50 (cinquenta) vezes. Em seguida, as fotos foram passadas para um computador para então serem analisadas pelo software Tracker versão 9.45, onde o mesmo faz parte de um projeto de Open Source Physics, ou seja, é um software gratuito para o uso do ensino de Física e qualquer pessoa pode baixá-lo, instalá-lo e utilizá-lo sem pagar. Com o Tracker é possível analisar as imagens e obter os ângulos de contato entre a água e o vidro conforme ilustrado na Figura3.1.
Figura 3.1: Imagem da medida do ângulo de contato entre a água e o vidro de uma gota despejada com a seringa de insulina, com o reflexo do vidro na parte de cima. Nesta imagem o ângulo obtido foi de $44,8^{\circ}$.

Figure 3.1: Image of the measurement of the contact angle between the water and the glass of a dropped drop with the insulin syringe, with the reflection of the glass in the upper part. In this image the obtained angle was $44.8^{\circ}$.

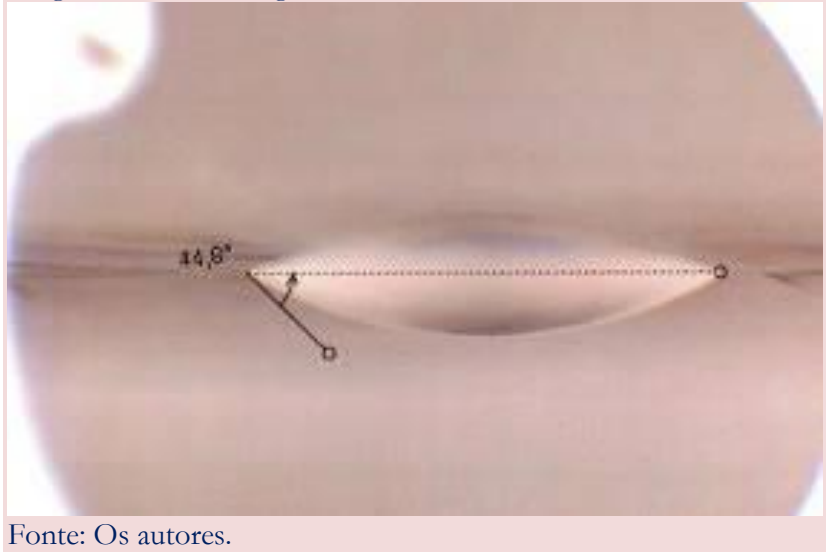

Para facilitar as medidas do ângulo, as imagens foram submetidas a um filtro (negativo), pois com ele, o contraste das bordas em relação ao fundo é mais visível. O ângulo de contado foi medido manualmente no programa com a ferramenta transferidor contida nele.

Foram feitas duas coletas de dados, uma para a seringa de insulina e a outra para a micro seringa, no primeiro momento, tem-se as medidas das gotas despejadas pela seringa de insulina. Foram despejadas várias gotas, uma posterior à outra com intervalo de tempo suficiente para fotografar-se duas vezes a mesma gota sendo o intervalo de tempo de $1 \mathrm{~s}$ entre essas duas fotos. Tirou-se fotografias de 15 (quinze) gotas, logo, têm-se 30 (trinta) fotografias analisadas através do software.

Obteve-se 30 (trinta) valores dos ângulos de contato uma para cada fotografia, como duas fotografias são de uma mesma gota, tirou-se o valor médio entre os ângulos encontrado para as duas imagens resultando assim em 15 (quinze) médias. Por fim, tirou-se o valor médio desses 15 (quinze) dados para então tirar-se o valor do ângulo e sua variação, os dados obtidos estão expostos na Tabela 1. 
Tabela 1 - Resultados referentes aos ângulos de contato obtidos entre a água e vidro (seringa de insulina).

Table 1 - Results referring to the contact angles obtained between water and glass (insulin syringe).

\begin{tabular}{|c|c|c|c|}
\hline$\overline{\text { Gotas }}$ & $\begin{array}{l}\text { Valor do Ângulo } \\
\text { de Contato da } 1^{a} \\
\text { Imagem }\end{array}$ & $\begin{array}{l}\text { Valor do Ângulo } \\
\text { de Contato da } 2^{a} \\
\text { Imagem }\end{array}$ & $\begin{array}{l}\text { Média Entre os } \\
\text { Ângulos de Contato } \\
\text { da } 1^{\mathrm{a}} \text { Imagem e da } \\
2^{\mathrm{a}} \text { Imagem }\end{array}$ \\
\hline $1^{\circ}$ & 47,9 & 47,3 & 47,6 \\
\hline $2^{o}$ & 42,1 & 47,4 & 44,6 \\
\hline $3^{\circ}$ & 40,7 & 45,4 & 43,1 \\
\hline $4^{\circ}$ & 41,3 & 44,9 & 43,1 \\
\hline $5^{\circ}$ & 47,9 & 48,4 & 48,2 \\
\hline $6^{\circ}$ & 46,8 & 44,9 & 45,9 \\
\hline $7^{\circ}$ & 44,9 & 47,5 & 46,2 \\
\hline $8^{\circ}$ & 46,1 & 45,2 & 45,7 \\
\hline $9^{\circ}$ & 45,8 & 43,4 & 44,6 \\
\hline $10^{\circ}$ & 45,6 & 41,7 & 43,7 \\
\hline $11^{\circ}$ & 44,8 & 45,1 & 44,9 \\
\hline $12^{\circ}$ & 45,7 & 46,9 & 46,3 \\
\hline $13^{\circ}$ & 43,8 & 44,6 & 44,2 \\
\hline $14^{\circ}$ & 44,2 & 44,8 & 44,5 \\
\hline $15^{\circ}$ & 45,3 & 44,8 & 45,1 \\
\hline \multicolumn{3}{|c|}{ Média das Médias dos Ângulos } & $45,2 \pm 1,5$ \\
\hline
\end{tabular}

Fonte: Os autores.

Com isso, o valor do ângulo de contato obtido a partir do aparato para as gotas despejadas pela seringa de insulina e medido com a utilização do software Tracker é de $45,2^{\circ} \mathrm{com}$ um erro de $\pm 1,5^{\circ}$, onde caracteriza-se a superfície como hidrofílica.

Com procedimento análogo ao anterior, foram fotografadas 26 imagens. Os dados coletados são relativos às gotas despejadas pela micro seringa, e com ela é possível ter maior controle do volume das gotas, sendo que neste caso o volume das gotas era de 0,1 $\mu \mathrm{l}$ (zero virgula um microlitro), os dados estão ilustrados está na Tabela 2.
Tabela 2 - Resultados referentes aos ângulos de contatos obtidos entre a água e vidro (micro seringa).

Table 2 - Results referring to the angles of contacts obtained between water and glass (micro serial).

\begin{tabular}{|c|c|c|c|}
\hline Gotas & $\begin{array}{l}\text { Valor do Ângulo } \\
\text { de Contato da } 1^{\mathrm{a}} \\
\text { Imagem }\end{array}$ & $\begin{array}{l}\text { Valor do Ângulo } \\
\text { de Contato da } 2^{\text {a }} \\
\text { Imagem }\end{array}$ & $\begin{array}{l}\text { Média Entre os } \\
\text { Ângulos de Contato } \\
\text { da } 1^{\mathrm{a}} \text { Imagem e da } \\
2^{\mathrm{a}} \text { Imagem }\end{array}$ \\
\hline $1^{\circ}$ & 44,6 & 44,6 & 44,6 \\
\hline $2^{\circ}$ & 43,6 & 45,8 & 44,7 \\
\hline $3^{\circ}$ & 44,7 & 46,3 & 45,5 \\
\hline $4^{\circ}$ & 45,8 & 46,2 & 46 \\
\hline $5^{\circ}$ & 47,6 & 46,5 & 47,1 \\
\hline $6^{\circ}$ & 44,3 & 45,3 & 44,8 \\
\hline $7^{\circ}$ & 43,9 & 44,8 & 44,4 \\
\hline $8^{\circ}$ & 47,7 & 44,1 & 45,9 \\
\hline $9^{\circ}$ & 44,3 & 43,3 & 43,8 \\
\hline $10^{\circ}$ & 44,8 & 46,3 & 45,6 \\
\hline $11^{\circ}$ & 44,8 & 45,1 & 45 \\
\hline $12^{\circ}$ & 47,1 & 45,2 & 46,2 \\
\hline $13^{\circ}$ & 45,4 & 46,3 & 45,9 \\
\hline \multicolumn{3}{|c|}{ Média das Médias dos Ângulos } & $45,3 \pm 0,9$ \\
\hline
\end{tabular}

Fonte: Os autores.

Assim, o valor do ângulo de contato obtido a partir do aparato para as gotas despejadas pela micro seringa e medido com a utilização do software Tracker é de $45,3^{\circ}$ com um erro de $\pm 0,9^{\circ}$, onde caracteriza-se a superfície como hidrofílica. É notório uma diminuição da flutuação do resultado, isso é devido ao maior controle do volume da gota.

Figura 3.2: Imagem da medida do ângulo de contato entre a água e o vidro de uma gota despejada pela micro seringa, com o reflexo do vidro na parte de cima. Nesta imagem o ângulo obtido foi de $45,3^{\circ}$.

Figure 3.2: Image of the measurement of the contact angle between the water and the glass of a dropped drop by the microsphere, with the reflection of the glass at the top. In this image, the obtained angle was $45.3^{\circ}$.

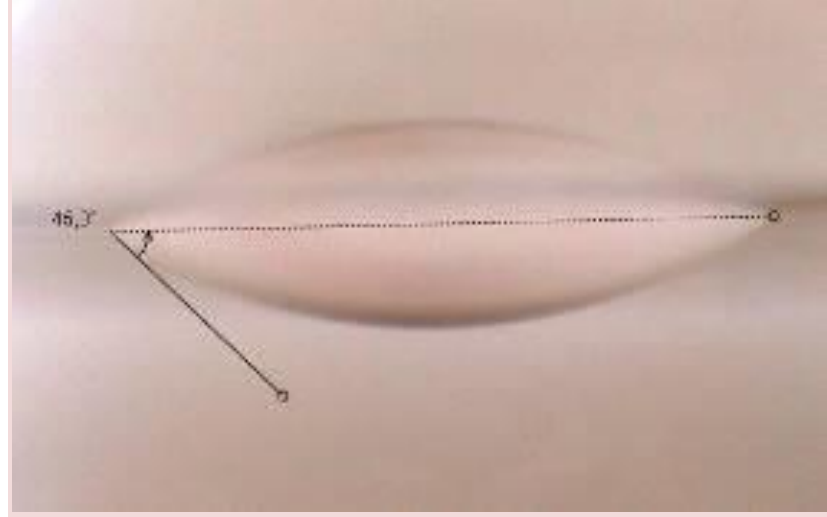

Fonte: Os autores. 
Estes resultados encontram-se na margem de resultados obtidos por equipamentos profissionais, pois conforme Pereira et. al., o ângulo de contato entre água e vidro utilizando o OCA 15 é de $45^{\circ}$ com um erro de $\pm 3^{\circ}$.

\subsection{Outros Dados}

\subsubsection{Thalia Geniculata}

De modo análogo ao procedimento anterior, também se calculou o ângulo de contato entre a Thalia Geniculata e a água (esta planta é encontrada com muita frequência em áreas de ressaca), os dados obtidos são para a face adaxial com cera. Para a coleta de dados escolheu-se a parte mais ao centro da planta, os dados estão lustrados na Tabela 3 e Tabela 4, a Figura 3.3 mostra duas imagens dos ângulos de contato obtidos através do software.

Tabela 3 - Resultados referentes aos ângulos de contato obtidos entre a água e a Thalia Geniculata (seringa de insulina).

Table 3 - Results referring to the angles of contact obtained between water and Thalia Geniculata (insulin syringe).

\begin{tabular}{|c|c|c|c|}
\hline Gotas & $\begin{array}{l}\text { Valor do Angulo } \\
\text { de Contato da } 1^{\text {a }} \\
\text { Imagem }\end{array}$ & $\begin{array}{l}\text { Valor do Ángulo } \\
\text { de Contato da } 2^{\text {a }} \\
\text { Imagem }\end{array}$ & $\begin{array}{l}\text { Média Entre os } \\
\text { Ângulos de Conta- } \\
\text { to da } 1^{\mathrm{a}} \text { Imagem e } \\
\text { da } 2^{\mathrm{a}} \text { Imagem }\end{array}$ \\
\hline $1^{\circ}$ & 157,3 & 157,1 & 157,2 \\
\hline $2^{\circ}$ & 158,5 & 158,3 & 158,4 \\
\hline $3^{\circ}$ & 157,8 & 156,6 & 157,2 \\
\hline $4^{\circ}$ & 156,7 & 156,6 & 156,6 \\
\hline $5^{\circ}$ & 158,4 & 158,2 & 158,3 \\
\hline $6^{\circ}$ & 158,6 & 158 & 158,3 \\
\hline $7^{\circ}$ & 156,4 & 156,7 & 156,5 \\
\hline $8^{\circ}$ & 157,1 & 157 & 157,1 \\
\hline $9^{\circ}$ & 157,7 & 158,2 & 157,9 \\
\hline $10^{\circ}$ & 159 & 158,5 & 158,7 \\
\hline $11^{\circ}$ & 156,5 & 157,5 & 157 \\
\hline $12^{\circ}$ & 156,4 & 156,3 & 156,4 \\
\hline $13^{\circ}$ & 159,2 & 158,8 & 159 \\
\hline \multicolumn{3}{|c|}{ Média das Médias dos Ângulos } & $157,6 \pm 0,9$ \\
\hline
\end{tabular}

Fonte: Os autores.

Assim, o valor do ângulo de contato obtido a partir do aparato para as gotas despejadas pela seringa de insulina e medido com a utilização do software Tracker é de $157,6^{\circ}$ com um erro de $\pm 0,9^{\circ}$, onde caracteriza-se a superfície como superhidrofóbica.
Tabela 4 - Resultados referentes aos ângulos de contatos obtidos entre a água e a Thalia Geniculata (microseringa).

Table 4 - Results concerning the angles of contacts obtained between water and Thalia Geniculata (microseringa).

\begin{tabular}{|c|c|c|c|}
\hline Gotas & $\begin{array}{l}\text { Valor do Angulo } \\
\text { de Contato da } 1^{\text {a }} \\
\text { Imagem }\end{array}$ & $\begin{array}{l}\text { Valor do Ângulo } \\
\text { de Contato da } 2^{a} \\
\text { Imagem }\end{array}$ & $\begin{array}{l}\text { Média Entre os } \\
\text { Ângulos de Contato } \\
\text { da } 1^{\mathrm{a}} \text { Imagem e da } 2^{\mathrm{a}} \\
\text { Imagem }\end{array}$ \\
\hline $1^{\circ}$ & 158,9 & 158,1 & 158,5 \\
\hline $2^{\circ}$ & 158,4 & 159 & 158,7 \\
\hline $3^{\circ}$ & 158,3 & 157,9 & 158,1 \\
\hline $4^{\circ}$ & 158,4 & 159,1 & 158,7 \\
\hline $5^{\circ}$ & 157,5 & 159,5 & 158,5 \\
\hline $6^{\circ}$ & 158 & 158,6 & 158,3 \\
\hline $7^{\circ}$ & 159,5 & 159,1 & 159,3 \\
\hline $8^{\circ}$ & 158,2 & 158,4 & 158,3 \\
\hline $9^{\circ}$ & 158,6 & 158,6 & 158,6 \\
\hline $10^{\circ}$ & 158,5 & 158,1 & 158,3 \\
\hline $11^{\circ}$ & 158,7 & 158,6 & 158,6 \\
\hline $12^{\circ}$ & 158 & 158,5 & 158,2 \\
\hline \multicolumn{3}{|c|}{ Média das Médias dos Ângulos } & $158,5 \pm 0,3$ \\
\hline
\end{tabular}

Fonte: Os autores.

Figura 3.3: Imagens das medidas dos ângulos de contato entre a água e a Thalia Geniculata: (a) gota despejada pela micro seringa onde o ângulo obtido foi de $158,5^{\circ}$. (b) gota despejada pela seringa de insulina onde o ângulo obtido foi de $156,7^{\circ}$.

Figure 3.3: Images of the contact angle measurements between watera nd Thalia Geniculata: (a) dropped by the micro syringe where the obtained angle was $158.5^{\circ}$. (b) dropped by the insulin syringe where the obtained angle was $156.7^{\circ}$.

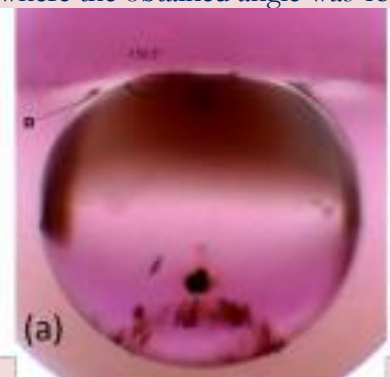

(b)

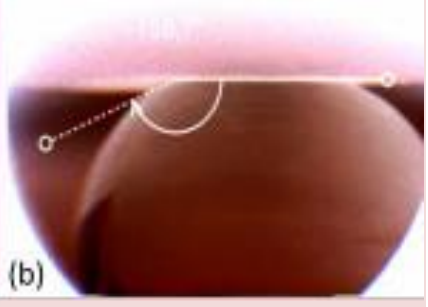

Fonte: Os autores.

Assim, o valor do ângulo de contato obtido a partir do aparato para as gotas despejadas pela micro seringa e medido com a utilização do software Tracker é de $158,5^{\circ}$ com um erro de $\pm 0,3^{\circ}$, onde caracteriza-se a superfície como superhidrofóbica. Também é notório uma diminuição da flutuação dos resultados, isso é devido ao maior controle do volume da gota, onde neste caso o volume da gota foi de $3 \mu \mathrm{l}$ (três microlitros).

Estes resultados também se encontram na margem de resultados obtidos por equipamentos profissionais, pois, conforme Figuei- 
redo et. al., o ângulo de contato entre água e a Thalia Geniculata para a face adaxial com cera é de $158,3^{\circ}$ com um erro de $\pm 0,44^{\circ}$.

\subsubsection{Colocasia Antiquorum Schottpara}

Seguindo o mesmo procedimento, analisou-se também a Colocasia Antiquorum Schottpara conhecido popularmente como tajá, cocó, comigo ninguém pode, etc. A parte analisada da planta foi a parte mais escura e mais ao centro, os dados estão na Tabela 5 e Tabela 6, a Figura 3.4 mostra dois dos ângulos de contato medidos no Tracker, um para uma gota despejada pela seringa de insulina e o outro para uma gota despejada pela micro seringa respectivamente.

Tabela 5 - Resultados referentes aos ângulos de contatos obtidos entre a água e a Colocasia Antiquorum Schottpara (seringa de insulina).

Table 5 - Results concerning the angles of contacts obtained between water and Colocasia Antiquorum Schottpara (insulin syringe).

\begin{tabular}{|c|c|c|c|}
\hline Gotas & $\begin{array}{l}\text { Valor do Ângu- } \\
\text { lo de Contato } \\
\text { da } 1^{\text {a }} \text { Imagem }\end{array}$ & $\begin{array}{l}\text { Valor do Ângu- } \\
\text { lo de Contato } \\
\text { da } 2^{\text {a }} \text { Imagem }\end{array}$ & $\begin{array}{l}\text { Média Entre os } \\
\text { Angulos de Con- } \\
\text { tato da } 1^{a} \text { Ima- } \\
\text { gem e da } 2^{\mathrm{a}} \text { Ima- } \\
\text { gem }\end{array}$ \\
\hline $1^{\circ}$ & 157,5 & 163,8 & 160,6 \\
\hline $2^{o}$ & 163,7 & 160,5 & 165,8 \\
\hline $3^{\circ}$ & 167,7 & 163,9 & 165,8 \\
\hline $4^{\circ}$ & 160 & 163,1 & 161,5 \\
\hline $5^{\circ}$ & 157,8 & 151,6 & 154,7 \\
\hline $6^{\circ}$ & 166,2 & 162,9 & 164,5 \\
\hline $7^{\circ}$ & 159,9 & 153,1 & 156,5 \\
\hline $8^{\circ}$ & 158,9 & 158,8 & 158,8 \\
\hline $9^{\circ}$ & 169,1 & 166 & 167,5 \\
\hline $10^{\circ}$ & 157,8 & 157,8 & 157,8 \\
\hline $11^{\circ}$ & 160,9 & 160,2 & 160,5 \\
\hline $12^{\circ}$ & 159,6 & 162,8 & 161,2 \\
\hline $13^{\circ}$ & 156,8 & 155,7 & 156,2 \\
\hline $14^{\circ}$ & 156,2 & 155 & 155,6 \\
\hline $15^{\circ}$ & 160,9 & 157,5 & 159,2 \\
\hline \multicolumn{3}{|c|}{ Média das Médias dos Ângulos } & $160,4 \pm 4$ \\
\hline
\end{tabular}

Fonte: Os autores.
Tabela 6 - Resultados referentes aos ângulos de contatos obtidos entre a água e a Colocasia Antiquorum Schottpara (micro seringa).

Table 6 - Results concerning the angles of contacts obtained between water and Colocasia Antiquorum Schottpara (micro syringe).

\begin{tabular}{|c|c|c|c|}
\hline$\overline{\text { Gotas }}$ & $\begin{array}{l}\text { Valor do Ângu } \\
\text { Contato da } 1^{\mathrm{a}} \\
\text { Imagem }\end{array}$ & $\begin{array}{l}\text { Valor do Ângulo } \\
\text { de Contato da } 2^{a} \\
\text { Imagem }\end{array}$ & $\begin{array}{l}\text { Média Entre os } \\
\hat{\text { Angulos de Contato }} \\
\text { da } 1^{\mathrm{a}} \text { e da } 2^{\mathrm{a}} \text { Imagem }\end{array}$ \\
\hline $1^{\circ}$ & 166,3 & 167,7 & 167 \\
\hline $2^{\circ}$ & 168,8 & 170,3 & 169,5 \\
\hline $3^{\circ}$ & 168 & 166 & 167 \\
\hline $4^{\circ}$ & 169,2 & 165,7 & 167,4 \\
\hline $5^{\circ}$ & 164,9 & 170,1 & 167,5 \\
\hline $6^{\circ}$ & 165,9 & 170,2 & 168,0 \\
\hline $7^{\circ}$ & 166 & 166,1 & 166,0 \\
\hline $8^{\circ}$ & 171,6 & 170,6 & 171,1 \\
\hline $9^{\circ}$ & 165,9 & 170,7 & 168,3 \\
\hline $10^{\circ}$ & 166,4 & 166,1 & 166,2 \\
\hline $11^{\circ}$ & 166,9 & 169,1 & 168 \\
\hline $12^{\circ}$ & 167,7 & 166,3 & 167 \\
\hline \multicolumn{3}{|c|}{ Média das Médias dos Ângulos } & $167,8 \pm 1,4$ \\
\hline
\end{tabular}

Fonte: Os autores.

Com isso, pode-se dizer que o valor do ângulo de contato segundo nosso aparato é $160,4^{\circ} \pm 4^{\circ}$ para gotas onde se usou a seringa de insulina e $167,8^{\circ} \pm 1,4^{\circ}$ para gotas onde se usou a micro seringa, aqui também é perceptível a diminuição na flutuação do resultado, isso porque o volume da gota manteve-se constante em $3 \mu$ l.

Figura 3.2: Imagens das medidas dos ângulos de contato entre a água e a Colocasia Antiquorum Schottpara, (a) imagem da gota da seringa de insulina e o ângulo medido foi de $160,2^{\circ}$; (b) imagem da gota da micro seringa e o ângulo medido foi de $170,3^{\circ}$.

Figure 3.2: Images of the contact angle measurements between water and Colocasia Antiquorum Schottpara, (a) image of the drop of the insulin syringe and the measured angle was $160.2^{\circ}$; (b) image of the microspheres drop and the measured angle was $170.3^{\circ}$.

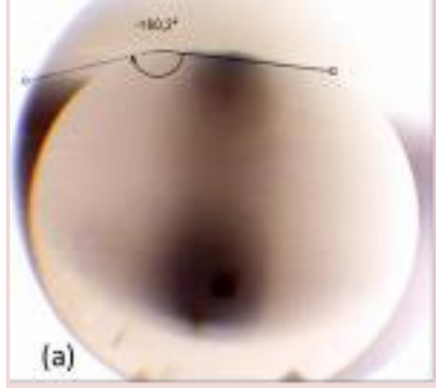

Fonte: Os autores.

Com base nos resultados acima podemos dizer que a superfície da Colocasia Antiquorum Schottpara é uma superfície superhidrofóbica, pois o valor do ângulo de contato encontrado 
foi superior a $150^{\circ}$. Este resultado não foi comparado a outros resultados feitos por equipamento profissionais, pois, ainda não se encontrou trabalhos que tenham o valor do ângulo de contato entre água e a Colocasia $A n$ tiquorum Schottpara.

\subsection{Vantagens e Desvantagens do Aparato}

Tem-se algumas vantagens ao usar-se o aparato como por exemplo o custo e manutenção deste é baixo; o software para a medida do ângulo é gratuito; sua construção e manuseio é simples fazendo com que qualquer pessoa pode estar construindo um e manuseando-o; alguém que nunca trabalhou com um medidor de ângulo de contato pode trabalhar com este facilmente; pesquisadores mais experientes ou amadores podem trabalhar e podem seguir suas pesquisas.

Certamente há vantagens, no entanto, há também desvantagens. Essas desvantagens são devido ao aparato não ser de origem comercial e sim construído a partir de "sucata", assim, pode-se dizer que essas vantagens presentes nesta pesquisa podem ser extinguidas trabalhando para melhoria do mesmo.

Pode-se citar como desvantagens a dificuldade na hora de estabilizar a câmera para a captura das imagens; o gotejamento sobre a superfície é manual e com isso qualquer desequilíbrio na mão resulta em uma má formação da gota; não há um controle preciso sobre o volume da gota usando a seringa de insulina, pois, ora põe-se uma gota com maior volume, ora põe-se uma gota com menor volume influenciando assim um ângulo de contato maior ou menor prejudicando a obtenção do resultado do mesmo, pois sabe-se que existe uma preocupação em manter o volume da gota praticamente constante (para evitar flutuações no resultado, como assim mostrados nos dados obtidos acima) como também o diâmetro da gota não ultrapassar os $10 \mu \mathrm{m}$, para que seja possível desprezar efeitos da força gravitacional; os ângulos são medidos manualmente e com isso os erros sistemáticos podem ser maiores como também o usuário pode manipular os dados; a adesão da gota na agulha quando despeja-se o liquido sobre uma superfície hidrofóbica. (PEREIRA et. al., 2012/ 2013)

\section{CONCLUSÕES E SUGESTÕES}

Há melhorias a se fazer neste aparato, pois, há limitações no mesmo e isso deve-se ao fato dele não ser profissional e sim construído de "sucata", contudo, mesmo o aparato sendo amador, o mesmo foi capaz de medir ângulo de contato entre a água e o vidro, entre água e a Thalia Geniculata e entre água e a Colocasia Antiquorum Schottpara mostrando resultados coerentes com demais resultados obtidos a partir de equipamentos profissionais. Os resultados estão ilustrados na Tabela 7 , ou seja, com base nos dados adquiridos nesta pesquisa pode-se dizer que o aparato funciona e alcançou seu objetivo principal que é medir ângulo de contato com um aparato de baixo custo e dizer se a superfície é hidrofóbica ou hidrofílica, e ainda este aparato caracterizou a superfície da Colocasia Antiquorum Schottpara como superhidrofóbica. 
Tabela 7 - Comparação entre os ângulos de contato obtidos com o aparato construído e os ângulos de contato obtidos por equipamentos profissionais.

Table 7 - Comparison between the contact angles obtained with the constructed device and the angles of contact obtained by professional equipment.

\begin{tabular}{|c|c|c|c|}
\hline Superfícies & $\begin{array}{l}\text { Água } \\
\text { vs } \\
\text { Vidro }\end{array}$ & $\begin{array}{l}\text { Água vs } \\
\text { Thalia } \\
\text { Geniculata }\end{array}$ & $\begin{array}{l}\text { Água vs Colo- } \\
\text { casia Antiquo- } \\
\text { rum Schottpara }\end{array}$ \\
\hline $\begin{array}{l}\text { Valor do ângulo de conta- } \\
\text { to para as gotas deposita- } \\
\text { das pela microseringa }\end{array}$ & $\begin{array}{c}45,3^{\circ} \pm \\
0,9^{\circ}\end{array}$ & $\begin{array}{c}158,5^{\circ} \pm \\
0,3^{\circ}\end{array}$ & $167,8^{\circ} \pm 1,4^{\circ}$ \\
\hline $\begin{array}{l}\text { Valor do ângulo de conta- } \\
\text { to para as gotas deposita- } \\
\text { das pela seringa de insuli- } \\
\text { na }\end{array}$ & $\begin{array}{c}45,2^{\circ} \pm \\
1,5^{\circ}\end{array}$ & $\begin{array}{c}157,6^{\circ} \pm \\
0,9^{\circ}\end{array}$ & $160,4^{\circ} \pm 4^{\circ}$ \\
\hline $\begin{array}{l}\text { Ângulos de contato } \\
\text { encontrado por equipa- } \\
\text { mentos profissionais }\end{array}$ & $\begin{array}{c}45^{\circ} \pm \\
3^{\circ}\end{array}$ & $\begin{array}{c}158,5^{\circ} \pm \\
0,3^{\circ}\end{array}$ & - \\
\hline $\begin{array}{l}\text { Erro relativo entre o valor } \\
\text { do aparato construído e o } \\
\text { valor de equipamentos } \\
\text { profissionais para as gotas } \\
\text { depositadas pela microse- } \\
\text { ringa }\end{array}$ & $0,7 \%$ & 0 & - \\
\hline $\begin{array}{l}\text { Erro relativo entre o valor } \\
\text { do aparato construído e o } \\
\text { valor de equipamentos } \\
\text { profissionais para as gotas } \\
\text { depositadas pela seringa } \\
\text { de insulina }\end{array}$ & $0,4 \%$ & $0,6 \%$ & - \\
\hline $\begin{array}{l}\text { Erro relativo do aparato } \\
\text { para as gotas depositadas } \\
\text { pela microseringa }\end{array}$ & $4,0 \%$ & $0,4 \%$ & $1,7 \%$ \\
\hline $\begin{array}{l}\text { Erro relativo do aparato } \\
\text { para as gotas depositadas } \\
\text { pela seringa de insulina }\end{array}$ & $6,6 \%$ & $1,1 \%$ & $5,0 \%$ \\
\hline
\end{tabular}

Fonte: Os autores.

Como sugestão para melhoramento do aparato, poderia desenvolver-se um software capaz de medir o ângulo de contato automaticamente ao analisar a imagem da gota obtida a partir da câmera. Devido a água ser apolar poderia estar aterrando a agulha, assim a gota não ficaria na mesma quando esta fosse despejada sobre uma superfície hidrofóbica e ainda estar trabalhando nas desvantagens deste aparato para aperfeiçoá-lo.

Como próxima pesquisa usando este aparato poderia-se medir o raio de curvatura de uma gota como também analisar a dinâmica do ângulo de contato quando a mesma evapora sobre a superfície escolhida.

\section{REFERÊNCIAS}

ASSIS, T. A. et al. Geometria fractal: propriedades e características de fractais ideais. Re- vista Brasileira de Ensino de Física, v. 30, n. 2, 2304 (2008). https://doi.org/10.1590/S1806$\underline{11172008000200005}$

BURKARTER, E. Construção de imagens por padrões hidrofóbico/hidrofílicos. 2006. 94 f. Dissertação (Mestrado em Física) Curso de Física, UFPR, Curitiba, 2006.

BURKARTER, E. Desenvolvimento de Superfícies Superhidrofóbicas de Politetrafluoretileno. 2010. 138 f. Dissertação (Doutorado em Física) - Curso de Física,UFPR, Curitiba, 2010.

DORING, L. J. R; LASMAR, O; FERREIRA, M. C. Cinética da tensão superficial e do ângulo de contato de gotas a partir de caldas com acaricida propargito e adjuvantes sobre folhas de café. In: CONBRAF - Congresso Brasileiro de Fitossanidade. Anais. Jaboticabal - SP.UNESP, 2013. p. 657 -661.

FERREIRA, M.C. Caracterização da cobertura de pulverização necessária para controle do ácaro Brevipalpusphoenicis (Geijskes, 1939) em citros. 2003. 64 f. Dissertação (Doutorado em Produção Vegetal) - Faculdade de Ciências Agrárias e Veterinárias, UNESP Jaboticabal, 2003.

Ferreira, L. M. V.: Revestimentos Hidrofóbicos. 2013. 77 f. Dissertação (Mestrado em Engenharia de Materiais) - Faculdade de Ciências e Tecnologias da Universidade Nova de Lisboa, FTC, Lisboa, 2013.

FIGUEIREDO, S. S. PRIOLI, R. Zamora, R. R. M.: Análise de superfícies foliares: Um estudo sobre a entropia como parâmetro de uniformidade superficial e a superhidrofobicidade de Folhas da Espécie Vegetal Thalia Geniculata (LINEU, 1753). 2015. 56 f. Dissertação (Mestrado) - Fundação Universidade Federal do Amapá, Programa de Pós-Graduação em Ciências Farmacêuticas, Macapá, 2015.

ONDA, T. et al. Super-Water-Repellent Fractal Surfaces. J. Phys. Chem, 1996, n. 100, p. 19512-1951. https://doi.org/10.1021/ip9616728 PEREIRA, A. C. M. FIGUEIREDO, F. M. 
F. BASTOS, F. C. C. NORONHA, V. T.: T3

- Ângulos de Contacto em Interfaces SólidoLíquido, Fenómenos Interfaciais MIB Ramo Engenharia Biológica $3^{\mathbf{0}}$ ano 2012/2013. Faculdade de Engenharia Universidade do Porto - FEUP.

Tracker Video Analysis and Modeling Tool. Disponível em: <http://physlets.org/tra cker/>. Acesso em: 10 out. 2016.

\section{(c) (1)}

License information: This is an openaccess article distributed under the terms of the Creative Commons Attribution License, which permits unrestricted use, distribution, and reproduction in any medium, provided the original work is properly cited.

Artigo recebido em 09 de setembro de 2019.

Avaliado em 29 de setembro de 2019.

Aceito em 29 de setembro de 2019.

Publicado em 02 de outubro de 2019.

\section{Como citar este artigo (ABNT):}

BARBOSA, Enoque de Sousa; SOUSA, Valéria Castelo Branco de; AGUILA, Victor Montero Del. Construção de um aparato de baixo custo para medir ângulo de contato. Estação Científica (UNIFAP), Macapá, v. 9, n. 1, p. 63-74, jan./mar. 2019. 